MedieKultur | Journal of media and communication research | ISSN 1901-9726

Article - Theme section

\title{
Digital distinctions: \\ mechanisms of difference in digital media use
}

\section{Stina Bengtsson}

MedieKultur 2015, 58, 30-48

Published by SMID | Society of Media researchers In Denmark | www.smid.dk The online version of this text can be found open access at www.mediekultur.dk

This article aims to understand the distinctive mechanisms of digital media use, seen in relation to cultural practices at large. The empirical material is a survey study of university students at the Business Administration, Media and Communication Studies, Political Science and Philosophy departments at Södertörn University, Sweden. The empirical analysis deals with the students' digital media use and preferences, and how these are related to their broader cultural practices and preferences. Specific attention is paid to the webpages the students mention in the survey, and how these are distributed among the groups. By showing detailed information on these areas, the mechanisms of difference of digital media use are revealed.

\section{Keywords}

Digital media use, Internet, acts of distinction, taste, Bourdieu, culture

\section{Introduction}

This article aims to understand digital media use as acts of distinction, and to explore the cultural mechanisms behind these distinctive acts. There is already a path well-trodden by scholars who have used Pierre Bourdieu's sociology of taste to understand digital media practices (cf. Van Dijk \&Hacker, 2003; Bengtsson \& Lundgren, 2005; Petrov \& von Feilitzen, 
2005; Kvasny, 2006; North et al., 2008; Zillien \& Hargittai, 2009; Robinson, 2009; Hargittai, 2010; Meyen et al., 2010; Gripsrud et al., 2011; Hollingworth, 2011; Kalmus et al., 2011; Danielsson, 2014). Many of them, however, have approached the uses of digital media as aspects of civic agency, and relate them to the "digital divide" and the democratic assets of the users. These studies have given us detailed information about how Internet use is related to democratic behaviours and engagement, and of the variety in how different groups with diverse economic and cultural capital use and relate to digital media. Although indisputably important, I see some shortcomings in continuing to only use Bourdieu's theory in this way to understand digital media use. Firstly, it rarely relates the user's online preferences and practices to interrelated practices in a wider cultural context and, as a result, overemphasises the boundaries between offline and online spheres. Digital media use and preferences are not isolated from other cultural practices. Rather, they are interwoven in the wider context of everyday life. Secondly, it does not regard online practices as distinctive acts in their own right, thus ignoring the significance of the Internet as a cultural (and not just political) sphere. In this article, I explore the distinctive mechanisms of digital media use, analysing digital media use as a cultural practice among others. Besides quantitatively revealing differences between user groups, I also dig deeper into the ways four groups of university students articulate their own use of digital media.

In doing this, I follow Jonathan Sterne's proposal to understand Internet use from an everyday life perspective, i.e. relating differences in Internet use and users' tastes, and preferences to distinctive acts in other cultural fields (Sterne, 2003). To understand the logic of practice of digital distinction, Sterne argues that:

$[T]$ echnologies do not have an existence independent of social practice, they cannot be studied in isolation from society or from one another. They are embodied in lived practice through habitus, and so even the basic 'phenomenological' aspects of technological practice and experience are themselves parts of the habitus. (Sterne 2003: 385)

Bourdieu always put forward a relational understanding of cultural practices, following (post)structuralism in understanding the meaning of cultural signs in relation to other cultural signs. The significance of signs is thus revealed "by everything which distinguishes it from what it is not and especially from everything it is opposed to; social identity is defined and asserted through difference." (Bourdieu, 1979,1984, p.172).

To understand digital media use as a distinctive cultural practice, and to adhere to a relational perspective on culture, I relate cultural practices and preferences online to those of user groups who are similar in terms of income, social class and background, their access to technologies, life situation and anticipated future, but who differ when it comes to cultural preferences and practices on a more general level. The four groups compared are university students at Södertörn University, Sweden, studying at the Business Administration, Media and Communication Studies, Political Science and Philosophy departments. My aim is to understand their distinctive mechanisms of digital media use by relating their digital 
practices, preferences and choices of online content to their wider cultural practices and preferences in everyday life. The empirical research questions guiding the analysis are the following: How are the students' cultural practices and preferences (in general) related to their online practices and preferences? How do they let online practices into their everyday lives and for what purposes do they use the Internet? Which web sites do the students visit most often and how are preferences distributed among the student groups? By presenting detailed information on these areas, we will see how the students act out the mechanisms of difference of digital media use.

\section{Earlier research}

There are two main strands in the field of Bourdieusian studies of Internet use and online practices: firstly, studies of how socio-cultural and economic heritage are linked to variations in online habits and Internet use (approached quantitatively as well as qualitatively), and secondly, studies of how users with different socio-economic statuses use different content and benefit from it in various ways. An example of the first is Eszter Hargittai's (2010) quantitative study, showing socio-economic status as an important predictor of how people incorporate the Internet in their everyday lives. These correlations are also supported by Van Dijk \& Hacker (2003), Petrov \& von Feilitzen (2008), and Kalmus, Realo \& Siibak (2011). Capital-enhancing activities include searching for information and acquiring knowledge and skills that are also useful in other areas in society, whilst less capital-strong users do not benefit from their Internet use in the same way (Hargittai \& Zillien, 2009).

In their qualitative study, North et al. (2008) found a strong link between the use of technology and the social class of young Internet users: how, when using digital media, experiences, objects, actions and accomplishments were directly related to the young people's habituses. In a similar study, Robinson (2009) has shown the relationship between access and non-access to digital media, habits of use, and in what ways users can benefit from these habits. These questions have also been understood by focusing on family relationships and the importance of habitus in cultural reproduction (Hollingworth et al., 2011; see also Schofield-Clark, 2013). Meyen et al. (2010) have studied the kinds of capital that are acquired online and which factors influence use patterns. In a diachronic comparison of Norwegian students from the years 1998 to 2008 (a study which has many similarities with the research presented here), Gripsrud et al. (2011) conclude that the most significant change in the cultural interests of students in the past decade is a decreasing interest in traditional highbrow culture. They argue that traditional forms of highbrow culture are becoming increasingly irrelevant in the students' lives, yet are more culturally distinctive as they still achieve a high degree of recognition.

One of the most important insights from the above is the importance of relating Internet use to the wider spectrum of cultural practices, as also suggested by Sterne (2003). In this study, I take the students' cultural preferences in general, and their highbrow cultural 
preferences in particular, as a vantage point for an analysis of their acts of distinction in everyday life online.

\section{Theoretical framework}

The students' digital media practices and preferences are understood in this study as part of their lifestyles, and analysed with their habitus as foundation. The habitus is created by an individual's social background, education and experiences. It is a cluster of continuous but still changeable dispositions (Bourdieu, 1990,p. 53) and can be described as the embodied form of an individual's cultural capital. Cultural capital and habitus are expressed by acts of distinction: ways to communicate and create one's identity by showing taste or distaste for cultural practices and artefacts. Bourdieu described the mechanisms behind these practices in this well-known quote:

\footnotetext{
Taste classifies, and it classifies the classifier. Social subjects, classified by their classifications, distinguish themselves by the distinctions they make, between the beautiful and the ugly, the distinguished and the vulgar, in which their position in the objective classifications is expressed or betrayed. (Bourdieu, 1979/1984, p.6)
}

This article aims to reveal the acts of distinctions the students make in their digital media use. As suggested by Jonathan Sterne, I study the students' use of digital media in relation to each other and to other cultural practices. Generally, acts of distinction work by expressing taste in the less common, the less accessible and the more unusual. According to Bourdieu:

\footnotetext{
In cultural consumption, the main opposition, by overall capital value, is between the practices designated by their rarity as distinguished, those of the fractions richest in both economic and cultural capital, and the practices socially identified as vulgar because they are both easy and common, those of the fractions poorest in both these respects. (Bourdieu, 1979/1984, p. 176)
}

The relationship between distinctive manners in the students' cultural consumption and taste at large, will thus be used as a background for our understanding of the mechanisms of distinction in digital media use.

\section{Research design and methods}

In a typology of Internet users, Meyen et al. (2010) put forward the "virtuosi" as the most advanced. "Virtuosi" can no longer imagine a life without the Internet and are "always online." They are young, upper middle class, highly educated and use the Internet in a way that enables them to accumulate both cultural and social capital.' The students in this study share many characteristics with the "virtuosi." As university students they are gener- 
ally middle class (according to their subjective understanding of class), between 20-25 years old, and on their way to becoming highly educated.

The empirical material is a survey study of students of Business Administration (BA), Media and Communication Studies (MCS), Philosophy (Phil), and Political Science (Pol) at Södertörn University, Sweden. These groups were chosen for their diversity within the societal "field of power" (Bourdieu, 1989/1996, 1992/1996). The questionnaire was distributed to all student groups at the four departments, in their classrooms, between 3 September and 2 October 2012. ${ }^{2}$ The population consists of 672 students and the sample equals 425. As a result, the response rate is $63 \% .{ }^{3}$ The fact that the survey study was conducted in the students' study environment has both advantages and disadvantages. On the one hand, the students were familiar with their environment and the people around them when filling in the questionnaire. On the other hand, the surroundings of the university environment may have influenced them to exaggerate their preferences for legitimate culture when answering the questions. As it is the relationships between the four student groups that are under observation, these possible effects equally affect all four groups. There is a large majority of women among the respondents ( $62 \%$ female students), however, this represents the distribution of students at the university overall (67\% female students). The large difference in numbers between the students from different departments (BA: 182, Phil: 42, MCS: 102, Pol: 99), also reflects the differences in student groups and their distribution within the university.

The questionnaire generally followed Bourdieu's mode of research in Distinction (1979/1984), covering everyday practices and cultural tastes: mass media (television, radio, press), literature, theatre, film, art, music, food, travel and digital media. The majority of the questions had closed answer alternatives, but many were open-ended, enabling the students to freely express their favourite web pages, social networking sites (SNSs), film director, bar/restaurant, author, etc. These open-ended questions have made it impossible to conduct multiple correspondence analyses, a method which Bourdieu himself often used for this kind of analysis. Nevertheless, they provide uniquely detailed information about the students' preferences and their ways of expressing them, that can then be combined with information on the broader patterns of structural differences between the four groups. In this analysis, I use questions with fixed answer alternatives to map the broader cultural tastes of the students. However, I also investigate further into the answers obtained from the open-ended questions, in order to understand how the students' preferences and practices of digital media use are structured, how they express differences, and what cultural hierarchies are constructed through this. Accordingly, the lack of multiple correspondence analyses is compensated for by the detailed insights into digital distinctions that can be found in the students' ways of answering the open-ended questions. This procedure also circumvents some of the shortcomings of quantitative methods, where respondents are forced to choose between alternatives that do not fit their individual habits or taste. 
To understand the mechanisms of difference in digital media use, I follow Bourdieu's relational approach, analysing the students' digital media use and preferences in relation to their practices and preferences in other cultural spheres. Van Deursen et al. (2011), have stated that survey studies have shortcomings when it comes to measuring actual practices and use patterns, as users have difficulties estimating the quantity of their actual use. In this case, the relational perspective diminishes this methodological weakness, as the core focus is the relationship between different practices and preferences measured in the same survey study. Consequently, the results will follow an internal logic affecting all parts of the empirical material in the same way. Instead of claiming an absolutely truthful representation of the students' actual tastes and habits, this study aims at identifying cultural values and mechanisms of difference visible in the students' answers about their cultural taste.

\section{The students: cultural practices in everyday life}

\section{Social background and current conditions}

According to Willekens \& Lievens (2014), parents' cultural capital ${ }^{4}$ is still a relevant category for understanding how the cultural interests and practices of young people develop. ${ }^{5}$ I will, therefore, present a brief overview of the students' social situations, backgrounds and their parents' cultural interests, as well as the student groups' own cultural preferences and practices. Students in general represent privileged groups in future society, although heading in different directions in the field of power (c.f. Bourdieu, 1989/1996, 1992/1996). They are also similar in many other ways. The majority of students in this study regard themselves as belonging to the lower-middle, middle or upper-middle classes (77\%). Their parents are also relatively highly educated. Only ten per cent of them are immigrants, but many are secondgeneration immigrants. They vary substantially, though, in terms of gender (although, as discussed earlier, in accordance with the gender balance among the students at large at this university). Bourdieu and many of his successors, have put forward the role of the mother in the cultural reproduction of families (Bourdieu, 2001; van Eijk, 1997; Willekens \& Lievens,

Table 1. The student groups' basic statistics (\%).

\begin{tabular}{lrrrr} 
& BA & Phil & MCS & Pol \\
Share of men & 31 & 71 & 25 & 49 \\
Middle class (lower, middle and higher) & 62 & 76 & 77 & 61 \\
Mothers with higher education qualifications & 54 & 71 & 69 & 50 \\
Fathers with higher education qualifications & 45 & 60 & 51 & 49 \\
Students with immigrant parents & 36 & 29 & 28 & 51 \\
\hline $\mathrm{N}($ sample) & 182 & 42 & 102 & 99 \\
\hline
\end{tabular}

* There are small variations in $N$ numbers between the different questions as specific individuals may have chosen not to answer one or several of the questions in the questionnaire. 
2014; Willekens, et al., 2014); therefore, I make a distinction between mothers' and fathers' cultural interests and education. ${ }^{6}$

At the core of Bourdieu's theory of distinction is cultural reproduction, i.e. the cultural preferences and practices inherited from parents, and when one examines how the students' describe their parents' interests, great variation is apparent. Wildlife activities, local history and politics appear as general parental interests in the survey material. Yet, there are greater differences when it comes to highbrow preferences, such as a taste for classical music, theatre and art films, an area in which the Phil (and MCS) students say their parents are more interested, compared with the claims made by the other students (see Table 2 below). The classic Bourdieusian concept of measuring books (in metres) in the family home during childhood also uncovers differences; the most common estimations among the students in the four groups are: BA: 0 metres (38\%, but 20\% estimated 1-4 metres), Phil: 30-49 metres (18\%), MCS: $5-9$ metres (20\%, but 18\% estimated 0 metres), Pol: $5-9$ metres (23\%).

Table 2. Parents' interest in highbrow culture among the student groups (\%)

\begin{tabular}{lrrrrr} 
& BA & Phil & MCS & Pol & Cramer's V \\
Theatre visits (\% often) & 31 & 69 & 51 & 46 & 0,244 \\
Alternative cinemas (\%) & 9 & 43 & 33 & 22 & 0,291 \\
Has visited Dramaten (\%) & 14 & 41 & 18 & 29 & 0,221 \\
Has been to Heron city (\%) & 50 & 22 & 33 & 42 & 0,193 \\
Has been to Cinemateket (\%) & 0 & 27 & 0 & 2 & 0,451 \\
Likes Titanic (\%) & 82 & 20 & 76 & 63 & 0,264 \\
Likes A Clockwork Orange (\%) & 22 & 67 & 47 & 38 & 0,222 \\
Likes ESC (\%) & 40 & 15 & 36 & 33 & 0,150 \\
Likes Two and a Half Men (\%) & 66 & 12 & 46 & 46 & 0,241 \\
Likes Kobra (\%) & 20 & 59 & 50 & 48 & 0,238 \\
\hline $\mathrm{N}($ sample) & 182 & 42 & 102 & 99 & \\
\hline
\end{tabular}

* There are small variations in $N$ numbers between the different questions as specific individuals may have chosen not to answer one or more of the questions in the questionnaire.

\section{Cultural practices and preferences}

Below, I present a small but illuminating part of the rich material provided by the survey study, so that I may argue that there are large variations in cultural taste between the four student groups. When asked what their favourite TV channel was, the most common answer from the BA students was the commercial channel, Kanal 5 (25\%), while the Phil students preferred the public service channel, SVT (58\%). MCS students preferred SVT (21\%) and Kanal 5 (21\%) equally, and the Pol students' most common choice was SVT (35\%). The Phil students went to the theatre more often than the others, attending the more highbrow (and publically financed) theatres such as the National Drama Theatre 
(Dramaten), Stockholm City Theatre, while the other students, to a greater extent, frequented private theatres to see musicals, farces, etc. The cinema visits among the students showed some similarity, given all groups often attend the dominant cinema company, SF Bio, in inner city Stockholm. However, there are considerable differences when it comes to other kinds of small-scale cinemas, such as alternative cinemas in Stockholm city, ${ }^{8}$ cinema visits in shopping malls outside the city, ${ }^{9}$ or the film club, Cinemateket. ${ }^{10}$ Examples of their film preferences also reveal their cultural tastes. The differences in preference between the four groups were considerable when asked about different films and TV shows, such as Titanic, A Clockwork Orange, the Eurovision Song Contest (ESC), Two and a Half Men, and Kobra (a culture programme on the Swedish public service channel, SVT). The fiction reading habits and preferences of the students follow the same patterns. The Phil students read more than the rest, preferring genres such as classics, serious fiction and poetry) while the remaining students, to a greater extent, prefer contemporary crime novels and adventure literature.

Table 3. Cultural practices and preferences in the student groups (\%) ${ }^{11}$

\begin{tabular}{lrrrrr} 
& BA & Phil & MCS & Pol & Cramer's V \\
Mothers interested in classical music & 22 & 46 & 27 & 28 & 0,136 \\
Fathers interested in classical music & 26 & 46 & 23 & 33 & 0,145 \\
Mothers interested in theatre & 42 & 64 & 61 & 46 & 0,148 \\
Fathers interested in theatre & 21 & 39 & 27 & 21 & 0,127 \\
Mothers interested in art house films & 20 & 34 & 25 & 20 & 0,093 \\
Fathers interested in art house films & 15 & 30 & 18 & 20 & 0,096 \\
\hline $\mathrm{N}$ (sample) & 182 & 42 & 102 & 99 & \\
\hline
\end{tabular}

"There are small variations in $N$ numbers between the different questions as specific individuals may have chosen not to answer one or more of the questions in the questionnaire.

\section{The students' cultural tastes}

These examples of the students' demographics and cultural habits show that, despite the fact that the students' background, social class and anticipated future are in many respects similar, they differ a lot when it comes to cultural reproduction, cultural habits and preferences in general. Gripsrud et al. (2011), have shown that taste for consecrated culture has lost substantial ground in the mental maps of Norwegian students between 1998 and 2008. However, despite this, or even because of this, this type of culture has become even more distinctive. The student groups in this study do not represent the wide spectrum of students analysed in the Norwegian study, and their preferences and tastes do not represent student groups beyond the ones analysed here. From the above, we can conclude that although these university students are homogenous when observed from a larger national population perspective, for example, there are differences between them when examined this closely. For example, when it comes to social background, the parents of the 
Phil students and the MCS students have higher education than the others (especially the mothers). There is also a lower rate of students with immigrant backgrounds among them. The differences between student groups are even more visible when it comes to parents' cultural interests: here, the Phil students stand out even more. The differences between the students' parents and their cultural interests (as perceived by the students) have their equivalents in the students' own cultural preferences. In practice, the Phil students in particular, but also the MCS students, prefer traditional, high culture and alternative culture to a larger extent than the others, .At the other end of the scale lie the BA students, who express a taste for more common and commercially organised popular culture.

With these expected but significant variances among the student groups as background, I will analyse the students' online use and preferences of digital media.

\section{The Internet in the students' everyday lives}

In this section, I present basic statistics measuring the students' use and preferences of digital media. Their access to digital technology is very good; almost all of them own their own laptops ${ }^{12}$ and mobile phones, ${ }^{13}$ but few of them own tablets. ${ }^{14}$

Table 4. Time spent online, per day (\%)

\begin{tabular}{lrrrrrrr} 
Department & Never & $>2$ hours & $\mathbf{3 - 5}$ hours & $\begin{array}{r}6-10 \\
\text { hours }\end{array}$ & $\begin{array}{r}\text { Most of my } \\
\text { time awake }\end{array}$ & Total & N \\
BA & 0 & 30 & 49 & 11 & 12 & 100 & 171 \\
Phil & 0 & 38 & 43 & 17 & 2 & 100 & 42 \\
MCS & 0 & 14 & 48 & 19 & 19 & 100 & 99 \\
Pol & 0 & 17 & 43 & 19 & 20 & 100 & 93 \\
\hline Total & 0 & 25 & 46 & 17 & 13 & 100 & 405 \\
\hline
\end{tabular}

According to Meyen et al. (2010), the most advanced category of young Internet users, the "virtuosi," can no longer imagine a life without the Internet and are "always online." According to the authors, they can accumulate both cultural and social capital from their Internet use. The "virtuosi" comprise a category of young, upper-middle class and highly educated users, therefore in many respects, they are similar to the university students analysed here. All of the students in the sample report (as do most young Swedes), that they use the Internet a lot in their everyday lives. ${ }^{15}$ Two points can be made initially: firstly, that the Phil and BA students claim to use the Internet less than the others (38\% and 30\% of them respectively, say they use the Internet less than 2 hours/day), and secondly, that the Phil students are also more reluctant than the others to see their Internet use as inseparable from their everyday lives (only two per cent of them agree that they use the Internet "most of [their] time awake"). 
Table 5. Purposes of Internet use (\%)

\begin{tabular}{lrrrrr} 
Department & Mainly studies/work & Mainly leisure activities & Both equally & Total & N \\
BA & 9 & 42 & 48 & 100 & 170 \\
Phil & 14 & 27 & 60 & 100 & 42 \\
MCS & 5 & 37 & 58 & 100 & 97 \\
Pol & 13 & 34 & 53 & 100 & 93 \\
\hline Total & 10 & 38 & 53 & 100 & 402 \\
\hline
\end{tabular}

When looking in more detail at how the students categorise their online activities, we see that those with the most highbrow cultural habits and preferences (the Phil students) claim to use the Internet somewhat differently from the others. Similarly, they claim more eagerly than the others that they use the Internet for work-related, rather than leisurerelated activities (although the Pol students also put forward the work purposes of their Internet use).

As already shown in earlier studies, everyday practices and preferences are expressed in online activities, in ways similar to those expressed offline (Petrov \& von Feilitzen, 2005; Hargittai \& Zillien, 2009; Hargittai, 2010). Thus, the Phil students, in line with their general highbrow preferences, claim to use the Internet to a greater extent to conduct their work/studies rather than for leisure (c.f. Danielsson, 2014). In the table below, we see the same patterns revealed in more detail. Although the four groups are homogenous in their use patterns, the Phil students differ from the rest, as they emphasise information searching to a greater extent, and claim to use the Internet less for social and recreational uses (e.g.music).

Table 6. Internet activities (\%) (Note that several answer alternatives could be chosen.)

\begin{tabular}{|c|c|c|c|c|c|c|c|}
\hline Dept. & $\begin{array}{r}\text { Search for } \\
\text { informa- } \\
\text { tion }\end{array}$ & $\begin{array}{r}\text { Communi- } \\
\text { cate with } \\
\text { friends }\end{array}$ & $\begin{array}{r}\text { Listen to } \\
\text { music }\end{array}$ & Play games & Watch TV & Other & $\mathbf{N}$ (sample) \\
\hline BA & 86 & 52 & 71 & 20 & 55 & 12 & 182 \\
\hline Phil & 93 & 41 & 62 & 21 & 50 & 14 & 42 \\
\hline MCS & 82 & 59 & 82 & 15 & 70 & 12 & 102 \\
\hline Pol & 89 & 47 & 70 & 15 & 66 & 13 & 99 \\
\hline
\end{tabular}

This section has mainly confirmed that the use patterns and preferences of the student groups within this study, reflect the use patterns of users rich in economic (and in particular) cultural capital, revealed in earlier research.

\section{Genres of online content as acts of distinction}

To gain a deeper understanding of the mechanisms behind Internet use as acts of distinction, I also allowed the analysed students to freely express which web sites they visit in their everyday lives (first, second and third alternatives). These open questions provide a great 
opportunity to map in a more detailed manner the differences in the diverse categories of Internet material that they use. I have categorised the open answers regarding web sites, and then ranked the different categories for all four groups. ${ }^{16}$ Note that the number of students differs between departments: for this reason, the number of answers also differs substantially between the four groups.

Table 7. The ten most visited web page categories ranked (per cent/number of answers) $)^{17}$

\begin{tabular}{|c|c|c|c|c|}
\hline Ranking order & BA & Phil & MCS & Pol \\
\hline 1. & SNS (25/102) & Press (22/20) & SNS (24/63) & SNS (22/54) \\
\hline 2 & Press (16/65) & Search $(22 / 20)$ & Press (19/49) & Press (18/44) \\
\hline 3. & Search (15/58) & SNS (16/15) & Search (16/43) & Search $(12 / 29)$ \\
\hline 4. & Email (7/28) & Email (14/13) & Email (7/18) & Shopping $(9 / 22)$ \\
\hline 5. & Shopping $(6 / 22)$ & TV $(8 / 7)$ & Blogs (7/17) & $\mathrm{TV}(8 / 19)$ \\
\hline 6. & Sport $(5 / 20)$ & Forums (3/3) & Shopping (5/14) & Email (7/16) \\
\hline 7. & TV (5/19) & Sport (3/3) & YouTube (4/10) & YouTube (6/14) \\
\hline 8. & YouTube (5/19) & YouTube (2/2) & Music $(2 / 6)$ & Sport (3/8) \\
\hline 9. & Blogs (4/15) & File sharing $(2 / 2)$ & Sport $(2 / 6)$ & Forum (3/6) \\
\hline 10. & Forums (2/9) & Radio $(2 / 2)$ & $\mathrm{TV}(2 / 5)$ & File sharing $(1 / 3)$ \\
\hline
\end{tabular}

First, it must be stated that the categories in table 7 are only the ten most frequently mentioned by the students, and that they also mentioned other kinds of web pages in the material. Three of the categories put forward by the BA, MCS and Pol students; shopping (e.g. IKEA.se, Zalando.se), humour (e.g. roosterteeth.se) and business/banking (e.g. Swedbank.se, "my bank" or Avanza.se) were though completely missing among the alternatives mentioned by the Phil students. Except for this, the same categories appear in the answers from all groups. This means that categories that are not in the answers in table 7 from one department (such as blogs or file sharing sites, e.g. The Pirate Bay), also appear in the answers from the other groups of students, only ranked lower in the list.

From the table above, we can conclude that all of the students use the Internet for various services provided by the traditional media (press, television, radio), and also searching for information and connecting with others via SNSs and email. All these practices are well in line with what earlier research has pointed out as use patterns of the privileged (Petrov \& von Feilitzen, 2008; Hargittai, 2010).

Another point that needs highlighting here, is the variation in ranking among the three most frequently mentioned categories, where the Phil students differ from the other groups in relation to their preferences.. Among the three other student groups, SNSs were mentioned most frequently, whereas the Phil students mentioned SNSs relatively less often. The Phil students' most common web page preference types were different kinds of online newspaper, followed by sites where one can search for information, after which came SNSs. Their first five categories of web sites also included television and email. MCS students mentioned blogs and music sites more frequently than the other groups, but mentioned 
television and discussion forums relatively less often. BA students and Pol students mentioned web pages where they could participate in discussion forums. They also mentioned shopping sites more frequently that the rest.

\section{Most frequented webpages as micro level distinctions}

In this section, I present detailed data concerning the following web categories: SNSs, newspapers, search sites and television. Television is ranked below the first three among the students' choices of web pages, but is a well-known distinction marker (e.g. de Solier, 2005; Kuipers, 2006). At this time, I do not count answers or rank categories or pages: I simply put forward all the alternatives mentioned at least once in each category, by each student group. Evidently, this does not provide any information about the students' motivations for their choice of web pages, but the large variety between the student groups regarding number and character of web pages, shows the differences in preferences between them. The analysis reveals differences in the types of web pages the students visit in the four selected categories, as well as in the kind of information the students used to specify the pages (in terms of how detailed the information is, etc.).

Table 8. SNSs mentioned in the open answers on most visited web page (Note: not ranked.)

$\begin{array}{ll}\text { Department } & \text { SNS web pages mentioned at least once } \\ \text { BA } & \text { Facebook, Instagram, Twitter, 4gag, Tumblr } \\ \text { Phil } & \text { Facebook, Twitter, manga.net } \\ \text { MCS } & \text { Facebook, Instagram, Twitter, Reddit, Soundcloud, Deviantart, Flickr, Tumblr } \\ \text { Pol } & \text { Facebook, Twitter, Instagram, Tumblr, 4gag, Pinterest, wimp.com }\end{array}$

The largest SNSs (Facebook, Twitter, Instagram) are mentioned in all but one of the groups. However, apart from that, there are differences regarding the number of SNSs used by the groups, as well as what kinds of networking sites they used. The Phil students mentioned considerably fewer kinds of SNSs than the others, while the MCS students used more specialised SNSs that serve many different interests (music, art, photography, etc.).

Table 9. Newspapers mentioned in the open answers regarding most visited web pages (Note: not ranked.)

$\begin{array}{ll}\text { Department } & \text { Newspapers: web pages mentioned at least once } \\ \text { BA } & \text { Aftonbladet, Daily Mail, DI, DN, Expressen } \\ \text { Phil } & \begin{array}{l}\text { DN, The New Yorker, nytid.fi, The Guardian, HBL.fi, SvD, Aftonbladet, DI, International } \\ \text { Herald Tribune }\end{array} \\ \text { MCS } & \text { Aftonbladet, dagensmedia.se, DI, DN, GP, SvD, Metro } \\ \text { Pol } & \begin{array}{l}\text { Aftonbladet, DN, Sportbladet, SvD Näringsliv, Expressen, SvD, The Guardian, Arbetar- } \\ \text { bladet, FriaTidningen, The Huffington Post }\end{array}\end{array}$


The most common type of answer in all groups is online versions of Swedish daily newspapers (Dagens Nyheter (DN), Svenska Dagbladet (SvD), Göteborgs-Posten (GP), Metro, Arbetarbladet, FriaTidningen) and tabloids (Aftonbladet, Expressen). More specialised daily papers are also mentioned (Dagens Industri (DI, financial news), Dagens Media (daily media news). Some also mention specific sections of daily papers such as SvD Näringsliv (financial news) or Sportbladet (the sports section of Aftonbladet). Besides these, international news is mentioned by (almost) all groups, including The Daily Mail (Mail Online), The New Yorker, The International Herald Tribune and The Huffington Post. All student groups, except the MCS students(who are less varied in their newspaper preferences and only read national newspapers), use the Internet to read international press. However, the Phil students, who are considerably fewer in numbers than other groups, mention a relatively higher number of foreign newspaper varieties than the others. ${ }^{18}$

Table 10. Information search sites mentioned in the open answers regarding the most visited web pages (Note: not ranked.)

$\begin{array}{ll}\text { Department } & \text { Information search sites: web pages mentioned at least once } \\ \text { BA } & \text { Google, Wikipedia, biblioteket.se, NE.se, IMDB, synonymer.se, hitta.se } \\ \text { Phil } & \text { Google, Wikipedia, IMDB, Google Reader, Google Translate, Libris, Openculture } \\ \text { MCS } & \text { Google, Wikipedia, IMDB, Stereogram } \\ \text { Pol } & \text { Google, Wikipedia, NE.se }\end{array}$

As university students, all groups of respondents use the Internet to search for information. Google and Wikipedia are mentioned by all groups, though NE.se (the Swedish national encyclopaedia), Internet Movie Database (IMDb) and various library services (biblioteket. se, Libris.se) also appear among the answers. It is worth noting that the Phil students' answers are more varied than the others, and they are also more detailed regarding the information they provide about the web pages (such as mentioning Google Reader and Google Translate, instead of just Google).

Table 11. Television sites mentioned in the open answers on most visited web pages (Note:

Not ranked.)

$\begin{array}{ll}\text { Department } & \text { Television: web pages mentioned at least once } \\ \text { BA } & \text { 1channel.in, free.tv.online, Gnula.biz, whatchseries.eu, TV3 Play, BBC, antena3. } \\ & \begin{array}{l}\text { es, FoxNews.com, kanal5play, Nyheter24.se, SVT, ViaPlay, watchseriesonline, } \\ \text { nyhetskanalen.se, TV6 Play }\end{array} \\ \text { Phil } & \text { Aljazeera, BBC, SVT, SVT Play } \\ \text { MCS } & \text { whatchseries.eu, SVT Play, SVT } \\ \text { Pol } & \begin{array}{l}\text { BBC, fotbollskanalen.se, SVT Play, Awaz.tv, Nyheter24.se, tubeplus.me, TVN24, SVT, } \\ \text { thedailyshow.com, TV8 Play, CNN }\end{array}\end{array}$


There is a significant difference in the numbers of sites, channels and programmes mentioned by the student groups. The Phil students and the MCS students mention significantly fewer TV sites and are also more limited in their taste in television. These two groups, in particular the Phil students, not only mention fewer TV stations than the other groups, but also (almost) exclusively mention public service channels (SVT, BBC) or high quality channels like Aljazeera. ${ }^{19}$ Among the BA and Pol students, the range of channels is much more varied. It is also more oriented towards Swedish and international commercial channels (TV3, Kanal 5, TV6, ViaPlay, etc.), and online streaming and downloading services (watchseriesonline, tubeplus, etc.).

There are big differences among the student groups both regarding the variety of answers in each category of web pages, and the specific web pages actually mentioned in each category. The Phil students have the most varied preferences for web pages when it comes to the daily press and search sites, and the least varied regarding SNSs and television. On the other hand, the MCS students present a great variety of SNSs, but fewer examples of traditional mass media. The Pol students show great variety in all categories except search sites, and the BA students are mostly varied regarding television and search sites. There is also a difference regarding the level of detail provided in the answers, relating to the sites in question.

\section{Distinctions in digital media use}

In this analysis, we have seen how the students articulate their own use of the Internet, the different categories of web pages they choose, and also how they articulate which pages they use (in terms of how detailed the information they offered was).

All the students in the study, as part of a future societal elite, do have some things in common: they all put forward information search sites as a significant utility, except for the MCS students. The Pol and BA students used the Internet a lot to consume television in various forms, and both the Pol and the Phil students used a large variety of newspapers online. Traditional mass media is thus a common choice of online content for (almost) all of the students. The group that differs the most in relation to the others in this respect, is the MCS students. They are rich in cultural capital as they have parents with many cultural interests and, in accordance with this, adhere to relatively highbrow taste patterns in general. They have however, to a higher extent than the other student groups, replaced many other kinds of cultural producers and distributors with a great variety of SNSs. They have an inherited taste for high culture (art, art films, etc.), but use social media sites to develop these interests.

Having revealed these differences in preference between the four student groups, it is time to return to the students' social and cultural background and discuss their patterns of preference in light of their cultural heritage. The respondents in this study generally have well educated and culturally interested parents, and they largely belong to the 
middle classes. Comparing the students' social background and their own cultural preferences however, revealed that the Phil and MCS students had parents with a more culturally oriented taste than the BA and Pol students. In everyday life, families and educational institutions reproduce such patterns (Bourdieu and Passeron, 1970/2008). The students' own preferences, seen from a broader cultural perspective, also reflect this kind of cultural reproduction.

\section{Online and offline accordance}

In the empirical material, we can see some evidence that more generalised taste patterns are reproduced in the students online preferences. Although all of these groups are resourcerich users of digital media, and adhere to the user-patterns of the privileged revealed by earlier research, ${ }^{20}$ the Phil students (those with the most developed taste for highbrow culture in general: theatre, film, etc), also differed from the others regarding their most visited webpages. Following this logic, there is an accordance between taste patterns offline and online, as the group of students that differed mostly from the others in their offline preferences (the Phil students), also differed the most regarding their online preferences. These patterns fulfil previous expectations, and confirm the relevance of using Bourdieu's theory when discussing digital media use as part of everyday cultures (Bourdieu, 1979/1984).

To see what kind of online content the highbrow preferences were related to more generally, we can look deeper into the online preferences of (especially) the Phil students. When their most common webpage responses were ranked, the Phil students put forward newspaper organizations and search sites as a favoured answer, compared with the other three student groups who all mentioned different kinds of SNSs as their number one choice of online content. As earlier research has found, cultural capital is correlated with use of news sites, information searching and e-mailing: the kind of content that the Phil students demonstrate preference towards, to a larger extent than the others. This could indicate that from the perspective of the university students participating in this study, SNSs have a less prestigious position than other kinds of online content.

However, what challenges this assertion, is that the MCS students who are also both comparatively rich in cultural capital and have preferences for consecrated culture, put forward SNSs both as their most common kind of webpage used. Of added interest, is that these students also revealed a great variety of SNSs among their favourite webpages, many with an explicitly cultural character. They seem (to a greater extent than the other student groups), to have replaced many other kinds of cultural producers and distributors with a great variety of SNSs. They have an inherited taste for high culture (art, art films, etc) but use social networking sites to develop these interests.

A dimension that also complicates the analysis, is the personalised character of SNSs. Except for the more culturally oriented SNSs, such as Deviantart or Flickr, it is difficult to know how the MCS (and other) students use their social networks. SNSs (like Facebook) 
can be news sources leading the way to many different newspapers all-over the globe, or have an inherently personal character, depending on the character of user and the people in his or her networks. From the material in this study, we can only speculate about this, and to more fully understand the sociology of taste within digital media use, we need qualitative research that aims to develop this kind of knowledge.

Although we can see differences in cultural capital and social background between these student groups, as well as differences in their online use patterns and preferences, the small number of respondents prevents me from drawing any wide-ranging conclusions from these facts, in terms of correlations. In the following section, I prefer to take a closer look at the answers the students gave in the open-ended questions. The differences in terms of quantity and variation, and the kind of information the students gave when mentioning their favourite web sites, can offer insight into the acts of distinction in digital media use.

\section{Mechanisms of difference}

This analysis has revealed differences in how the students expressed distinction in articulating their cultural interests. As already mentioned, the BA students' answers were the most varied regarding TV and information search sites, the MCS students expressed the greatest variety in their use of SNSs, the Phil students were the most varied in their use of newspapers and search sites, whereas the Pol students used a greater variety of sites in three of the four categories analysed here, i.e. TV, press and SNSs.

According to Bourdieu, distinctive acts are those that strive to express difference towards that which is regarded easy, common or mainstream (1979/1984,p.176). In this material, we can see three different mechanisms of difference expressed on three different levels. The first is the level of varying categories of web pages, revealed in the rankings of the categories. The second is the level of variety of sites within the different categories mentioned by the students. The third is the level of detail in the information provided by the answers. Expanding on this, the first mechanism of difference is to act distinctively, by opting out of a medium or media content. The Phil students' more restricted use of the Internet and their reluctance to blur the boundaries between online and offline spheres are examples of this. Another example is their more modest use of SNSs, visible in the lower number of SNS pages mentioned, and in the lack of diversity in their choices.

The second mechanism of difference works in the opposite way, by being detailed and varied regarding specific media content (and thus going beyond what is regarded mainstream). An example of this is the presentation among the MCS students of a broad variety of SNSs (such as DeviantArt, Flickr, or SoundCloud), reaching beyond the commonly used SNSs (such as Facebook and Twitter). The large variety of newspapers put forward by the Phil and Pol students, provide an additional example of this. 
The third and last mechanism of difference is in line with the second, and regards the level of detail in the information about what kind of media content is used. Mentioning Google Translate or Reader instead of just Google, or SuD Näringsliv instead of just SuD, are examples of this kind of mechanism.

\section{Concluding remarks and suggestions for future research}

The relationship between cultural and economic capital and the use of new media, have already been well explored by other scholars. ${ }^{21}$ In this article, I have strived to use the conclusions of earlier research as a vantage point for understanding how users with differing cultural preferences and habits show distinction in a new media environment.

This analysis has revealed the importance of micro-level analyses to understand digital media use from a cultural perspective. Although the information on web content provided by this study is detailed, digital media platforms (such as Facebook), can be used in a great variety of ways, and provide users with diverse kinds of content, depending on the character of their own personal networks. Therefore, it is important in future research, to investigate in further detail the behaviour of individuals when online, and how this relates to their wider cultural practices and preferences, qualitatively as well as quantitatively.

\section{References}

Bengtsson, S. \& Lundgren, L. (2005). The Don Quixote of Youth Culture: Media Use and Cultural Preferences among Students in Sweden and Estonia, Huddinge: Södertörn Academic Studies.

, Mariek, V. \& , R. (2013). 'Adolescents' school experience and the importance of having a "cool" mobile phone: Conformity, compensation and resistance?' Poetics, Vol. 41(3), pp. 265-293.

Buendía, N., Juarez, B \& Peercy, M. (2004). 'The Geographies of Difference: The Production of the East Side, West Side, and Central City School'. American Educational Research Journal. Vol. 41 (4), pp. 833-863.

Bourdieu, P. \& Passeron, J. (1970/2008). Reproduktionen: Bidrag till en teori om utbildningssystemet [La Reproduction]. Arkiv Förlag.

Bourdieu, P. (1979/1984). Distinction. A social critique of the judgment of taste. Cambridge (MA): Harvard University Press.

Bourdieu, P. (1986). 'The forms of capital'. In Richardson, J.J. (Ed.), Handbook for Theory and Research for the Sociology of Education. (pp. 241-258) Greenwood Press: New York

Bourdieu, P. (1989/1996): The State Nobility. Elite schools in the field of power. Cambridge: Polity Press.

Bourdieu, P. (1992/1996). The Rules of Art. Genesis and the structure of the literary field. Cambridge: Polity Press.

Bourdieu, P. (2001). Masculine Domination. Stanford University Press, Stanford, CA.

Bucht, C. \& Eva, H. (2013): Young People in the Nordic Digital Media Culture: A Statistical Overview Compiled by Catharina Bucht and Eva Harrie. The International Clearinghouse on Children, Youht and Media. Göteborg: Nordicom. 
Danielsson, M. (2014). Digitala distinktioner. Klass och kontinuitet i unga mäns vardag. (diss). Halmstad: Högskolan i Halmstad.

de Solier, I. (2005). 'TV Dinners: Culinary Television, Education and Distinction.' Continuum: Journal of Media \& Cultural Studies. Vol. 19(4), pp 465-481.

Gripsrud, J. Hovden, J.\& Hallvard, M. (2011) 'Changing relations: Class, education and cultural capital.' Poetics, Volume 39 (6), pp. 507-529.

Hargittai, E. (2010). 'Digital Na(t)ives? Variations in the Internet Skills and Uses among members of the "Net Generation"'. Sociological Inquiry, Vol. 80 (1), pp. 92-113.

Hollingworth, S. Mansaray, A. Allen, K. \& Rose, A. (2011): Parents' perspectives on technology and children's learning in the home: social class and the role of the habitus. Journal of Computer Assisted Learning, Vol. 27, pp. 347-360.

Kalmus, V.Realo, A. \& Siibak, A. (2011). 'Motives for Internet use and their relationship with personality traits and socio-demographic factors'. TRAMES, Vol. 15(4), pp. 385-403.

Kuipers, G. (2006). 'Television and taste hierarchy: the case of Dutch television comedy'. Media, Culture \& Society, vol. 28(3) pp. 359-378.

Meyen, M., Pfaff-Rüdinger, S., Düdenhöffer, K. \& Huss, J. (2010). 'The Internet use in everyday life: a typology of Internet users'. Media, Culture and Society, Vol. 32,(5), pp. 873-882.

North, S., Snyder, I. \& Bulfin, S. (2008). 'Digital tastes: Social class and young people's technology use'. Information, communication \& society, Vol. 11, (7), pp. 895-911.

Petrov, P. \& C von Feilitzen, C. (2005). Virtuellt rum och socialt rum: om IT i vardagslivet. Huddinge: Södertörn Academic Studies.

Robinson, L. (2009). 'A taste for the necessary: A Bourdieuian approach to digital inequality'. Information, Communication \& Society, Vol. 12, (4), pp. 488-507.

Selwyn, N. (2006). 'Digital division or digital decision? Non-users and low users of computers'. Poetics, Vol. 34, pp. 273-292.

Sterne, J. (2003). 'Bourdieu, technique and technology'. Cultural Studies, Vol. 17(3-4), pp. 367-389.

Van Deursen, A., van Dijk, J. \& Peters, O. (2011). 'Rethinking Internet skills: The contribution of gender, age, education, Internet experience, and hours online to medium- and content-related Internet skills'. Poetics, Vol. 39, pp. 125-144.

Van Dijk, J. \& Hacker, K. (2003): The Digital Divide as a Complex and Dynamic Phenomenon. The Information Society, Vol. 19, pp. 315-326.

Van Eijk, K. (1997). 'The impact of family background and educational attainment on cultural consumption: a sibling analysis'. Poetics Vol. 25, pp. 195-224.

Willekes, M. \& Lievens, J (2014). 'Family (and) Culture: The effect of cultural capital within the family on the cultural participation of adolescents'. Poetics, Vol. 42, pp. 98-113.

Willekens, M., Daenekindt, S. \& Lievens, J (2014). 'Whose Education Matters More? Mothers' and Fathers' Education and the Cultural Participation of Adolescents'. Cultural Sociology, Vol. 8, pp. 291-309

Zillien, N. \& Eszter, H. (2009). 'Digital Distinction: Status-Specific Types of Internet Usage'. Social Science Quarterly. Vol. 90(2), pp. 274-291.

\section{Notes}

1 C.f. the "addicts" who also use the Internet all the time, but in less beneficial ways.

2 I had access to all classes but one: one of the master classes at the Business Administration department.

3 With variations of 60 to $69 \%$ between the departments.

4 Understood as dispositions and practices, educational level and cultural goods in the home. 
5 Combined with the educational level and gender of the young themselves.

6 Parents' (particularly mothers') cultural capital as well as gender (and education) are important aspects of the cultural capital of young people (Willekens \& Lievens 2014). In this case, however, choice of academic discipline is more strongly correlated to cultural capital than gender (although, as seen above, there is a gender imbalance between the different disciplines). Therefore, I have checked Cramer's $V$ for the different correlations presented below and, in most cases, the students' disciplinary belonging correlated stronger to cultural practices and preferences than gender.

7 Cramer's $\mathrm{V}$ for the categories above correlated with gender are generally lower: mothers' interest in classical music/gender: 0.120; fathers' interest in classical music/gender: 0.098; fathers' interest in theatre/ gender: 0.052; mothers' interest in theatre/gender: 0.077; fathers' interest in artistic films/gender: 0.051; mothers' interest in artistic films/gender: 0.066.

8 E.g. Zita, www.zita.se, BioRio, www.biorio.se.

9 Heron city, www.heroncity.se.

10 Cinemateket, http://www.sfi.se/sv/Cinemateket/Stad/Stockholm/.

11 Similarly, when it comes to the students' own cultural practices and preferences, the relationship between cultural tastes and discipline overshadows the relationship between cultural tastes and gender. Only in one case (visits to the Swedish national theatre, Dramaten) was Cramer's V above 0.1 (0.101). But the relationship between visits to Dramaten and discipline had a Cramer's V value of 0.221 , which is significantly higher.

12 Laptops: BA 91\%, Phil 93\%, MCS 95\%, Pol 99\%.

13 Mobile phones: BA 95\%, Phil 98\%, MCS 100\%, Pol 99\%.

14 Tablets: BA $15 \%$, Phil $10 \%$, MCS 15\%, Pol 20\%.

15 Swedes aged 15-24 used the Internet in average 3 hours/day in 2012 (Bucht and Harrie, 2013: 15).

16 This kind of categorisation is, of course, difficult to undertake as many of the web pages mentioned by the students can be used in a variety of ways.

17 Examples of sites that represent the different categories in the table will follow in the next section of the article.

18 That there are two Finnish newspapers on the list indicates there is at least one Finnish student among the Phil students who keeps track of the news from their home country.

19 Although, of course, watching Aljazeera can be a way of keeping informed about one's home country, and not a distinctive choice.

20 C.f. Van Dijk \& Hacker (2003), Petrov \& von Feilitzen (2005), Kvasny (2006), North et al. (2008), Zillien/Hargittai (2009), Robinson (2009), Hargittai (2010), Meyen et al. (2010), Gripsrud et al. (2011), Hollingworth (2011), Kalmus et al. (2011),

21 C.f. Van Dijk \& Hacker (2003), Bengtsson \& Lundgren (2005), Petrov \& von Feilitzen (2005), Kvasny (2006), North et al. (2008), Zillien/Hargittai (2009), Robinson (2009), Hargittai (2010), Meyen et al. (2010), Gripsrud et al. (2011), Hollingworth (2011), Kalmus et al. (2011), Danielsson (2014).

Stina Bengtsson

Ph.D., Associate Professor

Media and Communication Studies

Södertörn University, Sweden

Stina.bengtsson@sh.se 